\title{
Different Yet Similar: Multi-Generational Professionals and Their Sentimentality Towards Reciprocity
}

\author{
Salvador G. Villegas \\ George Fox University
}

As the generational demographics of the American workforce have changed over time, it is crucial to identify if there are generational differences regarding the sentiment of reciprocity (Kolm, 1994), specifically among professionals. This quantitative study $(n=122)$ found that generational identity does not influence positive (rewarding) reciprocity, meaning that regardless of age, professionals willfully reciprocate in a mutually beneficial manner, affirming that reciprocity is a personal norm (Gouldner, 1960). Alternatively, this study found that negative (punishing) reciprocity is significantly correlated \& influenced by generational identity. Baby Boomers and Millennials show the highest contrast in negative reciprocity, with Millennials more willing to engage in punishing unkind behavior than their predecessors.

Keywords: multi-generational, reciprocity, Millennial, Baby Boomer

\section{INTRODUCTION}

The Golden Rule, an eye-for-an-eye, and quid-pro-quo are all idioms describing how people interact with one another through reciprocity in action. Not to be confused with altruism, reciprocity bases its power through symbiosis in which both parties benefit from helping one another (Trivers, 1971). Within business and economics, reciprocity can go beyond personal favors and exchanges. Professional reciprocity includes organizational reciprocity based on calculated impersonal business decisions (Belmi \& Pfeffer, 2015). Even through calculated business efforts, there appears to be a change in the way that American professionals are using reciprocal activities for business gain. Understanding the sentiment behind what causes professionals to reciprocate with one another for mutual benefit is the impetus for the research in this study.

For a practical example of how reciprocal engagement has changed in the modern business environment, one needs to look no further than local civic, service, and community-based organizations. Over the past several decades, social capital has deteriorated within these organizations; as evidenced by dwindling membership numbers (Arnett, 2014). This decrease is not caused by the resignation of old members per se, but instead new generations have decided not to embrace these types of social networking stalwarts (Putnam, 2000). Organizations that once thrived on professional business participation are now facing a shortage of potential members (Arnett, 2014; Serven, 2016). Several domestic organizations that once succeeded on reciprocity (e.g., Kiwanis, Rotary, and Lions Clubs), are not drawing near the number of new members as in generations past, while membership has continued to decrease (Eikenberry, 2007). There could be a multitude of factors as to why these types of networking 
groups are now fading. This research assesses if one of these factors could be a difference in reciprocal sentiment between different generations of working professionals. It is puzzling that these types of entities continue to struggle, as research has shown that actors who participate in reciprocal networking can access and generate higher income from relational connections than solely through individual efforts (Flap, 1999; Lin, 2001). It seems that neither public nor personal economic incentives are enough to keep professionals from growing these types of community organizations. Discovering the cause of this change in reciprocal engagement activities between different generations of professionals requires further investigation.

\section{Research Question}

This research is driven by the determination to discover if generational sentiments are a cause for this ideological shift away from civic engagement rooted in reciprocity. The research question for this study is:

\section{$\mathbf{R Q 1}$ - How do professionals feel about reciprocity?}

This study will test two related, yet independent hypotheses for this study. The primary hypothesis analyzes whether generational identities/groupings are correlated:

\section{$\boldsymbol{H}_{1}:$ The generational identity of professionals has a correlation to their sentiments towards reciprocity.}

The secondary hypothesis seeks to determine what (if any) measurable differences are identified in the results derived from this research:

$\boldsymbol{H}_{2}$ : There are significant differences in the individual sentiments that professionals have towards reciprocity.

In this research, the respective generational identities act as independent variables; whereas, the sentiment of reciprocity (both negative and positive) serves as the dependent directional variables. Differences, for this study, are identified in relation to sentiments of both negative and positive reciprocity.

\section{LITERATURE REVIEW}

Primarily, this research is a generational study identifying reciprocal sentiments among professionals. Professionals, regardless of industry, are those individuals who understand who they are (Slay \& Smith, 2011) and what they do for a living (Pratt, Rockmann, \& Kaufmann, 2006). This identity is constructed through the culmination of values, beliefs, attributes, experience, and motives of professionals (Schein, 1978). To identify generational sentiments towards reciprocity, the opinions of both current and former working professionals were collected through the completion of a short survey. The perspectives of working-age professionals (OECD, 2017) consist mainly of Baby Boomers (born between 1946 and 1964), Generation X (born between 1965 and 1980), and Millennials (born between1981 and 1997). Though once active in the workforce, the viewpoint of past/former working professionals including the Greatest Generation (born between 1901 and 1924) and the Silent Generation (born between 1925 to 1942) (Pew Research Center, 2018a) are also included in this research.

Generational consciousness has established a new lens to view this country (Poo, 2017). The generational demographics of the American workforce has shifted from Baby Boomers as the most significant working generational block, to now Millennials having become the largest share (Pew Research Center, 2018b). Millennials are now the largest generation participating in the U.S. labor force, representing $35 \%$ of the overall market with 56 million workers (Pew Research Center, 2018b). Generation Xers comprise slightly less than 33\%, with 53 million workers, and Baby Boomers now 
represent only $25 \%$ of the workforce, with 41 million participants (Pew Research Center, 2018b). Represented by fewer workers than in years past, the Silent Generation accounted for less than $2 \%$ of the working-age population (Pew Research Center, 2018b). Post-Millennials (Generation Y), meaning those born after 1996, account for less than $5 \%$ of the working-age population or 9 million workers (Pew Research Center, 2018b). Researchers have shown that previous generations (Silent Generation and the Greatest Generation) were more likely to be active in civic engagement compared to adults in current society (Putnam, 2000). Therefore, understanding the link between these distinct generations and their feelings towards reciprocity is timely and significant. The goals of this study are to fully understand the sentiment of reciprocity between different generations of professionals who operate within the current American workforce.

\section{Multi-Generational Workforce}

Generational shifts do not occur suddenly from one year to the next, but instead, there is a gradual change over time, impacting the overall identity of members within the cohort (Twenge et al., 2010). These identities are most easily identified due to the historical distance between them (Roberts, 2012). Generations working alongside one another is not a new concept in business, but one that has become a widely popular area of research (Woods, 2016). The current workforce contains one of the most diverse demographic of professionals who represent many generational eras (Abdul Malek \& Jaguli, 2018; Costanza et al., 2012; Stutzer, 2019). Even though individuals who actively participate in the modern workforce may work well with their multigenerational colleagues, researchers have identified definite differences in managerial and employee expectations stemming from each generational cohort (Thompson \& Gregory, 2012).

The characteristics and attributes of each of these generational constructs are not haphazard but instead defined by several differentiating factors. The study of generations goes beyond specific birth years, rather it encompasses a comprehensive understanding of generational identity, and the impact that these identities have on their members. Succinctly, generational identities are described as a genealogical based kinship (Lyons \& Kuron, 2014). These genealogical kinships (Lyons \& Kuron, 2014) provide more than just a common set of shared experiences, but they have also been shown to affect many areas in the lives of those represented by each group. Researchers have discovered that generational identity shapes: intrinsic values (Dunn, 2018; Urick, 2012), extrinsic values (Twenge et al., 2010), motivations (Abdul Malek \& Jaguli, 2018; Heyns \& Kerr, 2018), attitudes (Stutzer, 2019), work ethic/advancement (Abdul Malek \& Jaguli, 2018; Milligan, 2014), workplace behavior (Heyns \& Kerr, 2018), career expectations (Dunn, 2018), media use (Pita, 2012), communication expectations (Stutzer, 2019), methods of learning (Milligan, 2014), and use of technology (Schullery, 2013).

The era that one is born into does not necessarily define their personal beliefs. However, these beliefs are most likely influenced by the era in which one was raised. Other non-generational forces that can heavily influence a person can include race, gender, religion, and ethnicity (Schullery, 2013). What is important to note is that everyone is unique and may have an outlook that is completely dissimilar from those of their peers (Lyons \& Kuron, 2014; Stutzer, 2019). Additionally, human action and subsequent reaction can change quickly from situation to situation (Villegas et al., 2019). Experience in a multigenerational workforce allows managers to learn from their diverse employees and gather information on how to lead (Harris, 2017).

\section{Reciprocity}

Attempting to understand the primary foundations of cooperation among people is a central theme in the behavioral science disciplines (Gachter \& Herrmann, 2009), including sociology, economics, political science, psychology. (Perugini et al., 2002). The concept of reciprocity has been researched for decades, and yet much division still exists as to the precise definition and scope of this concept as it is clouded in ambiguity (Gouldner, 1960). Even economic theorist Adam Smith (2006) has argued, that kindness yields kindness. In showing how reciprocity has significant societal importance within historical and social structures, Becker (1956) argued that humans are reciprocal (homo reciprocus) without ever defining the 
term reciprocity. Building upon the work of Becker (1956), Gouldner (1960) postulated that reciprocity supersedes cultural relativism as a universal truth, requiring two interconnected demands (a) people should help those who have helped them and (b) people should not injure those who have helped them (p. 171).

The moral claim in this theory suggests that to function as a society, it is necessary to pay back or reciprocate to those that have helped an individual at some later point in time, while never intentionally harming those who have assisted in the past. Superseding cultural relativism, this norm functions in a way that can be evident in all moral codes throughout the world (Gouldner, 1960). Current research has further substantiated this claim and argued that this theory could be characterized as an internalized social norm (Perugini et al., 2002). Within this conceptual framework lies the understanding that cooperation is based on a pattern of exchanges of actions and obligations for repayment. This norm, having both personal and inter-organizational (professional) implications, can be relevant in social networks, especially in the business world. One of the potential issues identified by this norm at both the individual and firm-level is the potential that people/organizations will only enter relationships with others that can reciprocate, while unintentionally neglecting the needs of those that genuinely need assistance (Gouldner, 1960).

A condition of reciprocity is that it involves voluntary, two-way transfers in both directions between involved parties, whereas altruism or gift-giving is merely a one-way transfer of goods or services (Kolm, 1994). Kolm (1994) argued that the sentiment which fuels reciprocal actions is the obligation to find balance among transferring parties. This research agrees with the premise set by Gouldner (1960) that reciprocity is a globally practiced and moral norm that can be accompanied by social pressure for adherence, good social relations, gratitude, and a sensation of moral indebtedness to continue reciprocal relationships (Kolm, 1994). Past researchers further argue that reciprocity is manifested within the economic systems of family matters, traditional economies, firms/organizations, and so forth (Kolm, 1994). Falk and Fischbacher (2006) argued that people reward good actions (positive reciprocity) and punish those actions that are unkind (negative reciprocity). Through their research, Falk and Fischbacher (2006) have concluded that kindness within reciprocal transactions is both the intention as well as the consequence of the reciprocal activity. The transverse of this position, unkindness, has also shown to be both a result and impetus.

Much like personal acts of reciprocity, organizations have been able to capitalize on relationships where the practice of I'll patronize you if you patronize me has become normal within large and small firms (Stocking \& Mueller, 1957). As researchers have demonstrated the difficulty in defining the concept of reciprocity relating to inter-personal exchanges, the same is true in coming to an accepted understanding as to the ambiguous nature of business reciprocity (Stocking \& Mueller, 1957). Traditionally, organizational reciprocity has been understood as the inter-firm dealings of independent organizations; whereby, each entity makes appropriate concessions for the mutual business interest of each company (Stocking \& Mueller, 1957). Some theorists have argued that organizations, being a nonliving entity, build reciprocal social capital and cooperation due to the existing personal relationships of actors within partnering firms (Adler \& Kwon, 2002; Barney \& Hansen, 1994; Goldstein et al., 2011; Oliveria, 2013); whereas, others argue that personal trust among actors has little influence on interorganizational trust activities like reciprocity (Ring \& Van De Ven, 1994; Zaheer et al., 1998). Because individuals who have authoritative control within reciprocating firms are the ones, who dictate the operations of their respective organizations, an element that is critical in the creation of productive relationships among all stakeholders in the implementation of cooperation (Goldstein et al., 2011).

Extant literature has been clear that generational cohorts have unique perspective on a several different aspects of life (intrinsic values (Dunn, 2018; Urick, 2012), extrinsic values (Twenge et al., 2010), motivations (Abdul Malek \& Jaguli, 2018; Heyns \& Kerr, 2018), attitudes (Stutzer, 2019), work ethic/advancement (Abdul Malek \& Jaguli, 2018; Milligan, 2014) which are caused by shared life experiences. Much research exists on the expectation of generational cohorts within their working environment; however, a glaring gap exists in the literature relating to multi-generational business professionals and their personal perception of reciprocity. The literature on reciprocity is abundant with theoretical findings of how individuals and organizational actors (Tangpong, Li, \& Hung, 2016) operate 
within the context of professional business dealings. There is little research, however, on professional sentiment towards reciprocity as a generational cohort. This research fills this void and adds to the body of knowledge on this subject.

\section{METHODOLOGY}

This research sought to identify the existence of any correlations and/or differences between generational cohorts and the way that they feel about reciprocity from a professional perspective. Participants for this survey were a sample of known professionals who operate primarily in the Pacific Northwest. All survey invitations were sent and accepted through a digital platform only, as a paper option was not available. The invitations were distributed to professionals regardless of age, industry type, and experience. A previously validated survey questionnaire was used (Dohmen et al., 2009; Richter et al., 2013) to collect both demographic and experiential answers from business professionals. This specific instrument is a short six-question survey measuring reciprocal sentiment that utilizes a sevenpoint Likert scale to determine the feelings of individuals towards reciprocity where $(1)=$ Does not apply to me at all, (4) = Neutral, and (7) = Applies to me perfectly.

As each respondent is a professional, it is assumed that they are likely to think of their answers with a business mindset (Belmi \& Pfeffer, 2015). These responses provide information as to how professionals feel regarding reciprocity while also including their sentiments towards organizational reciprocal activity. Participants were sent a link to the survey via an e-mail/direct message invitation with results collected through a reputable online platform. Respondents and their answers were completely anonymous. As a means of identifying the appropriate generational identity and qualifying factors of each respondent, the data collected included pertinent demographic information such as respondent age, gender, industry, years of professional business experience, and organization type (for-profit, not-for-profit). Each respondent was given explicit directions to answer each survey question from a professional point of view, rather than a personal perspective. Only fully completed surveys were used for this study, with incomplete surveys being discarded.

\section{Survey Participation}

The survey invitation was sent to a sample of 394 professionals operating primarily within the Pacific Northwest. A total of 126 surveys were collected; $122(\mathrm{n}=122)$ of which answered all questions relating to both generational cohort and sentiment toward reciprocity. The overall response rate was $31.97 \%$, with a completion rate of $96.8 \%$. From this survey, $96.7 \%$ of the respondents represent the three largest workforce generations, Baby Boomers (54 to 72 years old - 14 respondents), Generation X (38 to 53 years old - 50 respondents) and Millennials (22 to 37 years old -54 respondents) (Figure 1). Comparatively, the working population of the American workforce is $97 \%$ represented by these three generational cohorts (Stutzer, 2019). There was minimal participation from both those professionals representing the Silent Generation (73+ years old -3 respondents) with $2.46 \%$ of the responses and those that represent Generational Z (21 years old and younger -1 respondent). 


\section{FIGURE 1 RESPONDENT'S GENERATIONAL COHORT REPRESENTATION}

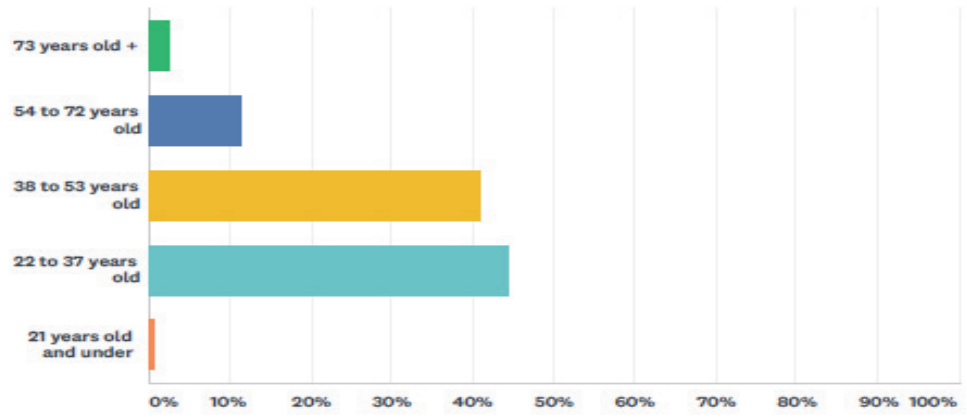

\begin{tabular}{l|rr}
\hline ANSWER CHOICES & RESPONSES & 3 \\
\hline 73 years old + & $2.46 \%$ & 14 \\
\hline 54 to 72 years old & $11.48 \%$ & 50 \\
\hline 38 to 53 years old & $40.98 \%$ & 54 \\
\hline 22 to 37 years old & $44.26 \%$ & 1 \\
\hline 21 years old and under & $0.82 \%$ & 122 \\
\hline TOTAL & & \\
\hline
\end{tabular}

This level of participation from these smaller groups was not unexpected as the members of the Silent Generation are past the full retirement age of 67 (Blanchett, 2018), and most likely not active as in professional activities as during their youth. There was only one response from a professional representing Generation Z (post-Millennials), accounting for $0.82 \%$ of all survey responses. As the oldest representatives of this cohort are only beginning to mature into adulthood, and representing only $1 \%$ of the American workforce (Stutzer, 2019), limited participation from this group was also anticipated. The percentage of participants across each generational demographic was similarly representative to the workforce age of across the nation, though not an exact equivalence.

\section{Results}

There are two hypotheses tested within this research study. As utilized by past researchers on this subject matter (Belmi \& Pfeffer, 2015; Chollet et al., 2014; Falk \& Fischbacher, 2006; Goldstein et al., 2011), a correlational analysis has been deemed as the appropriate examination to test the first hypothesis: $\mathrm{H}_{1}$ : The generational identity of professionals has a correlation to their individual sentiments towards reciprocity. Upon analyzing the median distribution of each variable based on the grouping of appropriate survey measures/items, there are not any large degrees of variability between the respondent groups (Figures $2 \& 3$ ). 
FIGURE 2

GENERATIONAL MEDIAN DIST. - POSITIVE

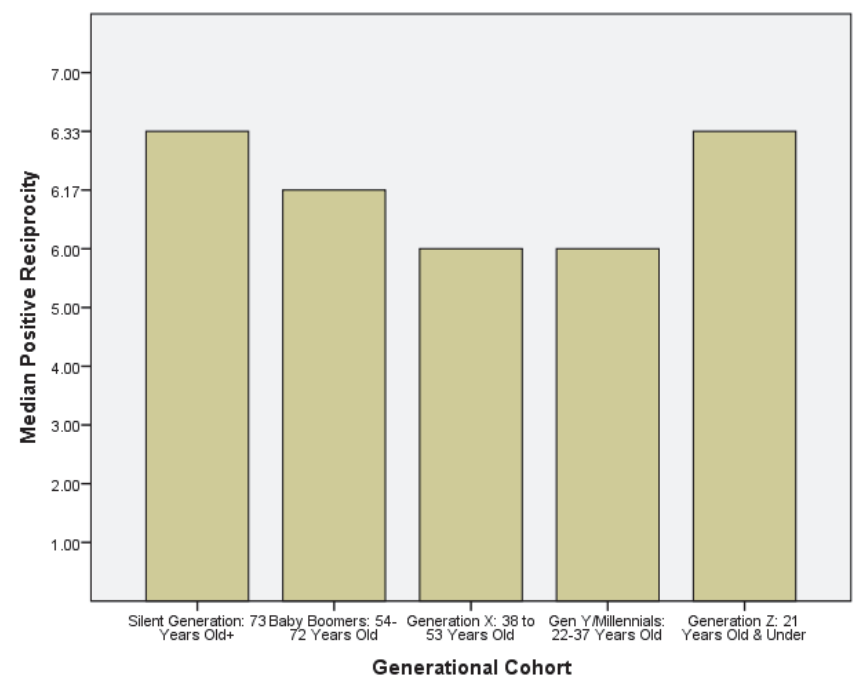

FIGURE 3

GENERATIONAL MEDIAN DIST. - NEGATIVE

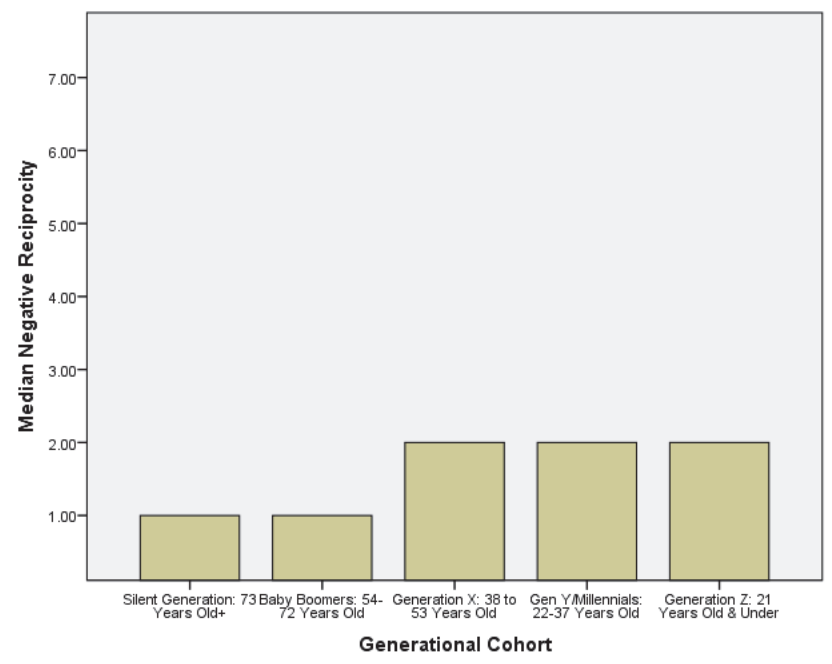

With the linear relationship of positive reciprocity and generational cohort, a Pearson R Correlation test was utilized to identify if a bivariate correlation exists between these two variables. The correlational analysis revealed that there does not exist a statistically significant correlation between positive reciprocity and generational identity. This data directionally rejects $\mathrm{H}_{1}$, thus supporting the null hypothesis.

Due to a non-parametric data, a Spearman's Rho correlational analysis was used to correlate the negative reciprocity dependent variable and the independent variables within this study (industry, experience, generational cohort, gender, education level, and reciprocal evolution). The findings of this analysis were statistically different than that of the positive reciprocity variable. This analysis shows that indeed a professional's generational cohort is statistically correlated with negative reciprocity with a $\rho=$ 0.24 , which is statistically significant at $p=0.02$ (Table 1 ). As this data shows a monotonic relationship 
between variables, this correlation itself denotes a small effect size with a $\rho=0.24$, which is equal to the correlation coefficient for these types of analyses.

TABLE 1

SPEARMAN'S RHO VARIABLE CORRELATION MATRIX

\begin{tabular}{|c|c|c|c|c|c|c|c|c|}
\hline & & 1 & 2 & 3 & 4 & 5 & 6 & 7 \\
\hline 1 & Industry & 1.00 & & & & & & \\
\hline 2 & Experience & -0.14 & 1.00 & & & & & \\
\hline 3 & Generation & -0.05 & $-.40 * *$ & 1.00 & & & & \\
\hline 4 & Gender & -0.11 & 0.07 & -0.12 & 1.00 & & & \\
\hline 5 & Education & 0.12 & 0.04 & -0.10 & $.27 * *$ & 1.00 & & \\
\hline 6 & Evolution & 0.02 & -0.11 & $.22^{*}$ & -0.12 & -0.11 & 1.00 & \\
\hline 7 & Negative Rec & $-0.19^{*}$ & $-.26 * *$ & $.21 *$ & $.24 * *$ & 0.15 & -0.01 & 1.00 \\
\hline
\end{tabular}

Through this correlational analysis, there does exist a statistically significant correlation between negative reciprocity and generational identity. This finding directionally supports $\mathrm{H}_{1}$ : The generational identity of professionals does have a correlation to their individual sentiments towards reciprocity while rejecting the null hypothesis for positive reciprocity.

\section{Generational Differences}

The second hypothesis of this study seeks to determine what (if any) significant differences are identified in the results derived from this research: $\mathrm{H}_{2}$ : There are significant differences in the individual sentiments that professionals have towards reciprocity. With ordinal data from different generations, an analysis of variance (ANOVA) was determined to be the appropriate test to determine if there exists a statistically significant difference in the means of each variable.

TABLE 2

ANOVA - NEGATIVE RECIPROCITY

\begin{tabular}{llllll}
\hline & Sum of Squares & Df & Mean Square & F & Sig. \\
\hline Between Groups & 8.487 & 2 & 4.244 & 3.294 & .041 \\
Within Groups & 148.153 & 115 & 1.288 & & \\
Total & 156.640 & 117 & & & \\
\hline
\end{tabular}

The results of the one way between subjects ANOVA for generational cohort on positive reciprocity variable did not show a statistically significant relationship, affirming the null hypothesis for positive reciprocity. The negative reciprocity variable did show a statistically significant relationship between groups with $F(2,117)=3.29$ with a significance of $p=0.04$. An eta squared test showed a $\eta^{2}=.054$, resulting in a small effect size for this relationship. This means that $5.4 \%$ of the variability in negative reciprocity can be accounted for by the variability in generational identity.

The ANOVA has already identified that there are statistically significant differences between negative reciprocity and generational identity. This post-hoc test serves to identify which groups have identified mean differences amongst one another. Comparing the three groups with the highest response rates (coincidently, those that also make up a large majority of the current workforce), the Tukey HSD 
has shown that there are no significant differences between all three groups, but rather differences only between two of the three (Table 3).

TABLE 3

POST-HOC TUKEY HSD: NEGATIVE RECIPROCITY

\begin{tabular}{|c|c|c|c|c|c|c|}
\hline \multirow{2}{*}{$\begin{array}{l}\text { (I) Generational } \\
\text { Cohort }\end{array}$} & \multirow{2}{*}{$\begin{array}{l}\text { (J) Generational } \\
\text { Cohort }\end{array}$} & \multicolumn{3}{|l|}{ Mean } & \multicolumn{2}{|c|}{$95 \%$ Confidence Interval } \\
\hline & & Difference & Std. & $\mathrm{SiO}$ & Lower & Upper \\
\hline \multirow{3}{*}{$\begin{array}{l}\text { Baby Boomers: } 54- \\
72 \text { Years Old }\end{array}$} & Generation X: 38 to & & & & & \\
\hline & 53 Years Old & -.72 & .34 & .10 & -1.53 & .10 \\
\hline & $\begin{array}{l}\text { Gen Y/Millennials: } \\
\text { 22-37 Years Old }\end{array}$ & $-.87^{*}$ & .34 & .03 & -1.68 & -.06 \\
\hline \multirow[t]{2}{*}{$\begin{array}{l}\text { Generation X: } 38 \text { to } \\
53 \text { Years Old }\end{array}$} & $\begin{array}{l}\text { Baby Boomers: } 54- \\
72 \text { Years Old }\end{array}$ & .72 & .34 & .10 & -.10 & 1.53 \\
\hline & $\begin{array}{l}\text { Gen Y/Millennials: } \\
\text { 22-37 Years Old }\end{array}$ & -.16 & .22 & .76 & -.69 & .37 \\
\hline \multirow[t]{2}{*}{$\begin{array}{l}\text { Gen Y/Millennials: } \\
\text { 22-37 Years Old }\end{array}$} & $\begin{array}{l}\text { Baby Boomers: } 54- \\
72 \text { Years Old }\end{array}$ & $.87^{*}$ & .34 & .03 & .06 & 1.68 \\
\hline & $\begin{array}{l}\text { Generation X: } 38 \text { to } \\
53 \text { Years Old }\end{array}$ & .16 & .22 & .76 & -.37 & .69 \\
\hline
\end{tabular}

*. The mean difference is significant at the 0.05 level.

Divergently from the positive reciprocity variable, negative reciprocity identified a difference between Baby Boomers and Millennials that has a statistically significant $\mathrm{p}$-value at $p=0.03$. The generation sandwiched between these two, Generation X, did not demonstrate a statistical significance between either their predecessors or successor generations. These findings support $\mathrm{H}_{2:}$ There are significant differences in the individual sentiments that professionals have towards reciprocity and reject the null hypothesis $\mathrm{H}_{3}$.

\section{DISCUSSION}

Specifically and central to this study is the understanding of how professionals spanning five different generations feel about reciprocal behavior, both positively and negatively. This study has shown primarily that even though positive and negative reciprocity may be opposite sides of the same personal norm (Gouldner, 1960), they operate completely separate of one another. Even when tested within the scope of this research, the positive and negative reciprocity variables are not correlated to one another, affirming the findings of past research studies (Egloff et al., 2013; Richter et al., 2013). By affirming the null hypothesis for positive reciprocity, this research argues that professionals feel positive reciprocal behavior (i.e., rewarding kindness with balanced kindness) is a practice that can be valued between all generations regardless of age. The same cannot be said for negative reciprocity as there are significant differences between groups. The directional components of reciprocity are different yet similar between each of the distinct generational cohorts. Simply, this study finds that generational identity does affect the way that individuals feel about professional retaliation. Through further explanation, the findings inform both the body of theoretical knowledge on this subject matter, while at the same time possessing the power to influence professional practice.

\section{Implications for Theory}

Primarily this study found that there does not exist a statistically significant correlation between a professional's generational cohort and their sentimentality towards positive reciprocity. Without a 
significant correlational link between positive reciprocity and generational perspectives, these findings uphold positive reciprocity as a personal norm that transcends age. When testing the negative reciprocity, however, generational identity has been found to be statistically significant.

The theoretical findings of this study are unique to both positive reciprocity and its opposing force, negative reciprocity. As many social/service groups have made the case that younger generations are choosing not to embrace membership in reciprocity based civic-oriented entities, causing many clubs to dwindle and close (Arnett, 2014; Serven, 2016). The findings of this research challenge the notion that generational identity influences feelings towards positive reciprocity. As the feelings of positive reciprocity have not changed through generations, these findings contest long-held beliefs that younger generations value positive reciprocity differently and to a lesser degree than previous generations. If anything, the results of this study advocate for the understanding that generational identity does not influence professional attitudes towards positive reciprocity in any significant fashion, while promoting the understanding that professionals of any age have similar feelings towards rewarding kind behavior. Professional sentiment found in this study supports the position that I'll patronize you, you patronize me (Stocking \& Mueller, 1957) regardless of age demographics.

The analysis of negative reciprocity, to understand the sentiment of punishing those who have been unkind, has produced a significant correlation to generational identity showing that age can influence an individual's willingness to engage in vengeance. This correlation infers that a professional's generational cohort influences their individual willingness to seek retribution when they feel that they have been harmed. These findings are new to the study of reciprocity in relation to generational dynamics. Though a professional may be willing to reward a kind action in a similar fashion regardless of age, when it comes to retaliation, professionals will most likely act differently based on which generation they are born into and identify with. These findings bring to light new information regarding the generational identity and its statistical influence on the sentimentality of negative reciprocity. When comparing negative reciprocity to the respondent's generational cohort, significant differences were discovered between the way that Millennials and their predominantly Baby Boomer parents (Migliaccio, 2017) feel about negative reciprocity, i.e., retaliating against those who are mean to us (Perugini et al., 2002). The data shows that Millennial professionals are more likely to be negatively reciprocal to others who have caused them harm than their Baby Boomer counterparts. There could be several factors as to why this difference exists within this sample. A potential explanation could be due to the optimistic nature of the Baby Boomer Generation (Harris, 2017) who look for the best in others, in comparison with Millennials who tend to be very achievement-oriented (Stutzer, 2019) and retaliate when they have been treated unkindly (Falk \& Fischbacher, 2006). Either way, this topic of differing opinions regarding negative reciprocity is deserving of further research.

\section{Implications for Practice}

The findings of this study extend beyond the theoretical body of knowledge but also apply to reciprocity in action. The results show that regardless of age, gender, or industry type, people actively practice positive reciprocity in their professional roles. In practice, this would mean that positive/rewarding interactions with professionals of all ages and generations should generate a similar response. If you help someone, they will most likely help you in return, or if you punish someone, they will most likely punish you in return (Caliendo et al., 2012). So how do professionals feel about reciprocity? This research decidedly demonstrates that professionals will interact with each other in a positively reciprocal manner when appropriate, regardless of age.

The willingness for professionals to embrace positive reciprocity with a variable mean of $\mu=6.092$ (on a seven-point scale) shows the high level of willingness to reciprocate kindness with kindness. A mean score near the maximum shows that most professionals in this study felt a willingness to positively reciprocate and undergo personal costs if necessary to return a favor in manner that is equivalent or equitable (Vaux Halliday, 2003) This study upholds extant literature in the belief that positive reciprocity appears to be a personal norm (Belmi \& Pfeffer, 2015; Gouldner, 1960) among all ages groups with little difference between them. For practicing professionals, participation in traditional service associations, 
clubs, or business organizations can still yield positive results as long one acts in a way that shows positive reciprocity to other members regardless of age. Professionally, and as a cautionary anecdote, this study shows that people are willing to punish one another based on harmful behavior, and age plays a determining factor.

Professionals should take note of these study findings as there are significant differences between the way that Baby Boomers and Millennials feel about negative reciprocity. The data shows that Millennial professionals demonstrate a significantly greater desire to seek revenge when they feel that they have been harmed in a professional setting. This could mean addressing issues with a manger when they feel that they have been treated unfairly by coworkers/customers etc. Comparatively, their Baby Boomer parents may continue to accept hurtful professional behavior as normal and acceptable. Managers who work in a multi-generational environment should take note of this generational attribute as it could provide a reason as to why a Millennial professional is more willing to seek reprisal of injustices when they feel harmed. Additionally, managers should also become aware that Millennials are less likely to accept perceived workplace injustices lying down as prior generations. This generational cohort is more willing to identify and speak out against apparent wrongs that are occurring in their professional environments.

\section{Study Limitations}

The findings of this study can influence both theory and practice through several subject matters; however, there is still more work to be done to expound on the findings in this study. Even though the results have proven validated and valuable, there are several factors which have possibly limited this study:

- Scope of this survey - This survey was bound by six questions/items, comprised of only two different dependent variables. Regardless of size, this questionnaire has been able to provide accurate findings that have shown to have both theoretical and practitioner value.

- Survey method of administration - This survey was only available through a digital electronic platform. While the assumption is that most professionals have internet access, there is a possibility that this method of survey administration limited the number of Traditionalist/Silent Generation respondents.

- Geographic location of survey participants - As all respondents were professionals primarily Pacific Northwest, it is unclear if there are potential cultural, geographic, and diversity biases/differences that could have affected the way these questions were answered.

- Voluntary response bias - A participant who completed this survey did so on a voluntary basis, which adds a potential for response bias. Respondents may overrepresent the opinions of those professionals who have strong opinions on reciprocity, while unintentionally underrepresenting those with differing views.

This study has allowed for a unique insight into the way that professionals today feel about rewarding and punishing those who act in a similar manner. Even with these potential study limitations, the benefit received from this research adds value to the practice of professional management and the factors that influence multi-generational values.

\section{Directions for Future Research}

In the final question of the survey, each respondent was asked whether they believed that their feelings towards reciprocity had changed over time. With over $60 \%$ of respondents answering either affirmatively or unsure if their beliefs have changed over time, it will benefit future researchers to run a longitudinal study that could identify if changes in reciprocal sentiment are taking place. Identifying the developmental process as generational cohorts change over time would help future researchers identify if reciprocal sentiment is dependent more on generational identity or possibly based on age/maturity level. This study opens the door for a longitudinal study to see if there is a measurable change in reciprocal sentiment from generation to generation. 


\section{CONCLUSION}

The findings of this study identify statistical differences between professionals regarding their sentimentality of reciprocity, while also demonstrating that there are undeniable similarities that show kindness regardless of generational identity. When professionals intentionally interact with the intent to either benefit or harm one another, reciprocity will continue to act the currency of society (Haidt, 2006). It is only when individuals harm one another, that age can influence the potential degree of punishment. It is not that professionals and their attitudes towards reciprocity have changed overtime per se, but possibly it is the methods, organizations, and mediums that professionals engage in which have changed. With professionals openly embracing/implementing professional concepts like paying it forward, Chamber of Commerce flash mobs, and heavily using websites like Yelp, Kickstarter, or GoFundMe.com, people are still putting reciprocity (both positive and negative) into action.

Furthermore, with technological advancements that allow for global communication in an instant through internet connections, the concept of community is ever-changing. No longer is a community only understood as the people that you live in proximity too, attend school with, or go to church with. The idea that civic engagement is built through memberships in local service clubs, PTO/school boards, bowling leagues, and garden clubs is antiquated and not non-inclusive of highly interactive a global marketplace. Now civic engagement can be created through participation in forums like social media groups, virtual educational cohorts, and online gaming communities that provide a connection with others whom you share a common bond. Though past researchers are skeptical that digital communities can translate into providing real and long term civic results, there is hope that these communities can benefit younger generations of Americans (Sander \& Putnam, 2009).

This study has shown that even as industries have come and gone, people are people and they will care for one another, or inversely hurt one another when they are the recipients of similar action. Even as minor differences between generational cohorts have been discovered within the realm of this study, it does not mean that people have changed to the point that they do not value reciprocity. Professionals very much feel the need to continue valuing the power of reciprocity within their industry, though at possibly different levels. Acting in a reciprocal manner is not mandatory nor legally required; however reciprocal activity continues to be both a boundless personal moral norm (Altmann et al., 2008; Belmi \& Pfeffer, 2015; Gouldner, 1960), while at the same time also being a transcendent societal norm (Goldstein et al., 2011). As research continues to explore the far-reaching power to reciprocal activity and sentiment, it is imperative to understand that even as technology, education, and communication evolve, human nature towards positive reciprocity has not changed generationally.

Professionals from all walks of life have demonstrated within this study that reciprocity is in and of itself a goal, not merely a means to a goal (Perugini et al., 2002). When professionals are shown kindness, they will possibly reciprocate kindness in the form of referrals, leads, partnerships, and additional business. If professionals are mistreated, then they may act vengefully and generate a loss of reputation of a rival, create disassociation, or, ultimately, advocate for another's professional failure. In the world of business and economics, professional reciprocation not only influences interpersonal and organizational relationships, but there can often be a direct economic impact on the bottom line. As argued by Kolm (1994), reciprocity can be explained as a sense of balance between that which is being transferred between parties. For professionals, finding this balance can be the difference between ultimate success or disaster, as the future can be the direct result of how they treat others. 


\section{REFERENCES}

Abdul Malek, M. M., \& Jaguli, A. R. (2018). Generational differences in workplace communication: Perspectives of female leaders and their direct reports in Malaysia. Journal of Asian Pacific Communication (John Benjamins Publishing Co.), 28(1), 129-150. https://doi.org/10.1075/japc.00007.abd

Adler, P. S., \& Kwon, S.-W. (2002). Social capital: Prospects for a new concept. Academy of Management Review, 27(1), 17-40. https://doi.org/10.5465/AMR.2002.5922314

Altmann, S., Dohmen, T., \& Wibral, M. (2008). Do the reciprocal trust less? Economics Letters, 99(3), 454-457. https://doi.org/10.1016/j.econlet.2007.09.012

Arnett, J. (2014, September 12). Service groups struggle to maintain memberships. McPherson Sentinel. Retrieved from http://www.mcphersonsentinel.com/article/20140912/news/140919692

Barney, J. B., \& Hansen, M. H. (1994). Trustworthiness as a source of competitive advantage. Strategic Management Journal, 15(S1), 175-190.

Belmi, P., \& Pfeffer, J. (2015). How "organization" can weaken the norm of reciprocity: The effects of attributions for favors and a calculative mindset. Academy of Management Discoveries, 1(1), 3657. https://doi.org/10.5465/amd.2014.0015

Blanchett, D. M. (2018). The impact of retirement age uncertainty on retirement outcomes. Journal of Financial Planning, 64-73.

Caliendo, M., Fossen, F., \& Kritikos, A. (2012). Trust, positive reciprocity, and negative reciprocity: Do these traits impact entrepreneurial dynamics? Journal of Economic Psychology, 33(2), 394-409.

Chollet, B., Géraudel, M., \& Mothe, C. (2014). Generating business referrals for SMEs: The contingent value of CEOs' social capital. Journal of Small Business Management, 52(1), 79-101. https://doi.org/10.1111/jsbm.12034

Costanza, D., Badger, J., Fraser, R., Severt, J., \& Gade, P. (2012). Generational differences in workrelated attitudes: A meta-analysis. Journal of Business \& Psychology, 27(4), 375-394. https://doi.org/10.1007/s10869-012-9259-4

Dohmen, T., Falk, A., Huffman, D., \& Sunde, U. (2009). Homo reciprocans: Survey evidence on behavioural outcomes. The Economic Journal, 119(536), 592-612.

Egloff, B., Richter, D., \& Schmukle, S. C. (2013). Need for conclusive evidence that positive and negative reciprocity are unrelated. Proceedings of the National Academy of Sciences, 110(9), E786-E786. https://doi.org/10.1073/pnas.1221451110

Eikenberry, A. M. (2007). Philanthropy, voluntary association, and governance beyond the state: Giving circles and challenges for democracy. Administration \& Society, 39(7), 857-882. https://doi.org/10.1177/0095399707306189

Falk, A., \& Fischbacher, U. (2006). A theory of reciprocity. Games and Economic Behavior, 54(2), 293315. https://doi.org/10.1016/j.geb.2005.03.001

Gachter, S., \& Herrmann, B. (2009). Reciprocity, culture and human cooperation: Previous insights and a new cross-cultural experiment. Philosophical Transactions of the Royal Society B: Biological Sciences, 364(1518), 791-806. https://doi.org/10.1098/rstb.2008.0275

Goldstein, N. J., Griskevicius, V., \& Cialdini, R. B. (2011). Reciprocity by proxy: A novel influence strategy for stimulating cooperation. Administrative Science Quarterly, 56(3), 441-473. https://doi.org/10.1177/0001839211435904

Gouldner, A. W. (1960). The norm of reciprocity: A preliminary statement. American Sociological Review, 25(2), 161. https://doi.org/10.2307/2092623

Haidt, J. (2006). The happiness hypothesis: Putting ancient wisdom to the test of modern science. London. England: Heinemann.

Harris, R. D. (2017). The realm of supervision. Supervision, 78(10), 6.

Kolm, S.-C. (1994). The theory of reciprocity and of the choise of economic systems: An introduction. Investigaciones Economicas, 18(1), 67-95. 
Migliaccio, J. N. (2017). Searching for the millions Millennials will need. Journal of Financial Service Professionals, 71(2), 37-42.

Oliveria, J. F. (2013). The influence of the social capital on business performance: An analysis in the context of horizontal business networks. Revista de Administração Mackenzie, 14(3), 209-235.

Perugini, M., Gallucci, M., Presaghi, F., \& Ercolani, A. P. (2002). The personal norm of reciprocity. European Journal of Personality, 17(4), 251-283. https://doi.org/10.1002/per.474

Poo, A-J. (2017). Generation X: being the change we need. Generations, 41(3), 90-92.

Richter, D., Metzing, M., Weinhardt, M., \& Schupp, J. (2013). SOEP scales manual. SOEP Survey Papers 138: Series C., 78.

Ring, P. S., \& Van De Ven, A. H. (1994). Developmental processes of cooperative interorganizational relationships. Academy of Management Review, 19(1), 90-118. https://doi.org/10.5465/AMR.1994.9410122009

Roberts, K. (2012). The end of the long baby-boomer generation. Journal of Youth Studies, 15(4), 479497. https://doi.org/10.1080/13676261.2012.663900

Sander, T., \& Putnam, R. (2009). Still bowling alone?: The post-9/11 split. Journal of Democracy, 21(1), 9-16. https://doi.org/10.1353/jod.0.0153

Smith, A. (2006). The Theory of Moral Sentiments (1790) (S. M. Soares, Trans.; 6th ed.). MetaLibri.

Stocking, G. W., \& Mueller, W. F. (1957). Business reciprocity and the size of firms. The Journal of Business, 30(2), 73-95.

Stutzer, K. (2019). Generational differences and multigenerational teamwork. Critical Care Nurse, 39(1), 78-81. https://doi.org/10.4037/ccn2019163

Thompson, C., \& Gregory, J. B. (2012). Managing Millennials: A framework for improving attraction, motivation, and retention. The Psychologist-Manager Journal, 15(4), 237-246. https://doi.org/10.1080/10887156.2012.730444

Trivers, R. L. (1971). The evolution of reciprocal altruism. The Quarterly Review of Biology, 46(1), 3557.

Twenge, J. M., Campbell, S. M., Hoffman, B. J., \& Lance, C. E. (2010). Generational differences in work values: Leisure and extrinsic values increasing, social and intrinsic values decreasing. Journal of Management, 36(5), 1117-1142. https://doi.org/10.1177/0149206309352246

Vaux Halliday, S. (2003). Which trust and when? Conceptualizing trust in business relationships based on context and contingency. The International Review of Retail, Distribution and Consumer Research, 13(4), 405-421. https://doi.org/10.1080/0959396032000129507

Villegas, S., Lloyd, R. A., Tritt, A., \& Vengrouskie, E. F. (2019). Human resources as ethical gatekeepers: Hiring ethics and employee selection. Journal of Leadership, Accountability and Ethics, 16(2). https://doi.org/10.33423/jlae.v16i2.2024

Woods, K. (2016). Organizational ambidexterity and the multi-generational workforce. Journal of Organizational Culture, Communications \& Conflict, 20(1), 95-111.

Zaheer, A., McEvily, B., \& Perrone, V. (1998). Does trust matter? Exploring the effects of interorganizational and interpersonal trust on performance. Organization Science, 9(2), 141-159. 